\title{
Needleless Contasure versus TVT-0 in Women with Stress Urinary Incontinence
}

\author{
Abd El-Moneim Abd El-Aziz Saleh1, Mahmoud Ahmed Ghareb1, \\ Diab Alsayed Mohamed Ibrahiem², Walid Mohamed Elnagar', \\ Mohammed Hassan Elsayed Barakat ${ }^{*}$ \\ ${ }^{1}$ Obstetrics \& Gynecology Department, Faculty of Medicine, Zagazig University, Zagazig, Egypt \\ ${ }^{2}$ Urology Department, Faculty of Medicine, Zagazig University, Zagazig, Egypt \\ Email: ${ }^{\star M o} 7$ mbarakat@gmail.com
}

How to cite this paper: Saleh, A.A., Ghareb, M.A., Ibrahiem, D.A.M., Elnagar, W.M. and Barakat, M.H.E. (2020) Needleless Contasure versus TVT-O in Women with Stress Urinary Incontinence. Open Journal of Obstetrics and Gynecology, 10, 1107-1121. https://doi.org/10.4236/ojog.2020.1080104

Received: May 31, 2020

Accepted: August 21, 2020

Published: August 24, 2020

Copyright $\odot 2020$ by author(s) and Scientific Research Publishing Inc. This work is licensed under the Creative Commons Attribution International License (CC BY 4.0).

http://creativecommons.org/licenses/by/4.0/

\begin{abstract}
Objectives: The aim of this thesis is to determine the clinical effectiveness, safety and cost-effectiveness of Single Incision needleless Mini-Slings compared with tension-free Standard Mid-urethral Sling in the surgical management of female stress urinary incontinence, but with less side effects. Methods: The study will be conducted in Zagazig University Hospitals. From 2018 to Sept. 2019, 40 cases were enrolled in the study and were randomized by envelope technique at the time of surgery to either a trans-obturator vaginal tape (TOT) or Needleless anti-incontinence procedure. The patients will be divided into 2 groups: Group 1 patient treated by standard sling (TOT). Group 2 those treated by mini-sling. Parameters in perioperative period such as operating time, intraoperative hemorrhage volume, length of stay in hospital, intraoperative complications, and postoperative pain of each patient were recorded. The sample size was calculated to be 40 cases ( 20 cases will be treated by standard slings, 20 case will be treated by mini-sling). Results: A total of 40 patients assessed for eligibility were randomized into Needleless groups. There were no significant differences in age, body mass index, process, parity, pad test or the assessment of preoperative quality of life between the two groups. In the perioperative period, statistically significant differences between the two groups were found in operating time, intraoperative hemorrhage volume, groin pain scores at $24 \mathrm{~h}$ after operation and length of stay in hospital $(\mathrm{P}<0.001)$. After two weeks of follow-up, a statistically significant difference between the two groups was found in groin pain/femoribus internus pain scores, but there were no significant differences in cure rates, pad test, complications or ICIQ-SF. After 1 year, there were no significant differences between the Needleless and TOT groups in cure rates, pad test, groin pain or ICIQ-SF (P > 0.05). Both groups registered a significant
\end{abstract}


improvement in the quality of life $(\mathrm{P}<0.001)$, but there were no significant differences between the two groups $(\mathrm{P}>0.05)$. Conclusion: We conclude that compared with the TOT surgery, single-incision Needleless sling in the treatment of female stress urinary incontinence is simpler and quicker and has less hemorrhage during surgery as well as faster recovery and it also can obviously reduce the inguinal region pains after operation and shorten hospital stays. In summary, single-incision Needleless sling is a kind of convenient, safe and effective minimally invasive surgery for urinary incontinence.

\section{Keywords}

Mini-Sling, Needleless, Stress Urinary Incontinence, TVT-O, TVT, Contasure

\section{Introduction}

Stress urinary incontinence (SUI) is involuntary urinary leakage with increase in intra-abdominal pressure (IAP); it affects up to one third of adult women worldwide. This leads to deterioration in quality of affected female life [1]. Women may consider SUI as a normal consequence of aging, or that few treatment options are available. SUI is more frequent after several deliveries and after menopause as a result of changes in the urethral support or the sphincter mechanism [2].

Surgery has become a standard treatment for female stress urinary incontinence. The surgical treatment can be roughly divided into seven categories, namely: Urehroplasty (Kelly, Kennedy, etc.), Retropubicurethropexy (Marchall-Marchitti Krantz, etc.), Colposuspension (Burch operation, Preyera), Urethral slings (Aldridge operation), Mid-urethral sling surgery, paraurethral injection, and artificial urinary sphincter [3].

As the operations are being improved and updated constantly, there are trials to find a treatment method that is not only effective, simple, easy to perform, with small trauma, and without long-term complications but also economical [4]. An evolution in treatment of SUI is trending toward less invasive techniques. The retropubic (TVT) and trans-obturator (TOT) minimally invasive slings are effective and relatively safe with cure rates between $80 \%$ and $90 \%$; however, there are inherent risks associated with the external needle passage through the abdomen or the groin [5].

In recent decades, mid-urethral sling has become the standard treatment for women with SUI when conservative treatments have failed. The typical outcome of a successful sling surgery corrects urethral hypermobility [6] (Karateke A., et al., 2009), which is often associated with SUI patients due to insufficient pelvic floor support to the urethra and can be clinically assessed by the cough stress test and Q-tip test [7]. By providing additional support to the urethra, the implanted sling helps to restore the continence mechanism.

The most recent contribution to technical modifications of surgical treatment 
occurred in 2006 with the introduction of the "single incision" concept [8]. Single incision mini-slings (SIMS) were created with theoretical advantages over standard mid-urethral slings (retropubic or trans-obturator). A shorter length of polypropylene tape is used; therefore, less mesh is inserted into the human body. Additionally, the insertion through a single vaginal incision produces a similar suburethral hammock to standard mid-urethral slings, avoiding both retropubic and groin blind penetration, thus theoretically maintaining high cure rates [9].

In 2009, Contasure ${ }^{\circledR}$ - accepted new minisling technique-has been developed maintaining the principle of a tension free sling-which was absent in $\mathrm{Mi}$ niarc ${ }^{\circledR}$ - . This had introduced the concept of Needleless sling, and is supposed to be effective like standard slings [10].

\section{Subjects and Methods}

\section{Setting of the study:}

The study was conducted in Zagazig University Hospitals, from 2018 to Sept. 2019 after acceptance of IRB department of our university.

\section{Population of the study:}

Women suffering from stress urinary incontinence.

Inclusion criteria:

- Women aged 18 years or over with SUI,

- failed or declined conservative treatment,

- All women will have urodynamic stress incontinence.

Exclusion criteria:

Women will be excluded if they have one or more of the following:

- Anterior wall or Apical Prolapse,

- Previous incontinence surgery for stress incontinence,

- Neurological conditions e.g. Multiple sclerosis, spinal cord injuries,

- Previous Pelvic irradiation.

Type of study: Clinical trial.

\section{Sample size:}

40 cases ( 20 cases will be treated by standard slings, 20 cases will be treated by mini-sling).

\section{C-Operative Design:}

Steps of performance and technique:

All patients were subjected to:

\section{1) Complete history taking:}

With stress on leakage of urine (type, amount and frequency). Past history of neurological disorders affecting the bladder and medical disorders such as diabetes mellitus, history of obstructed labor or gynecological history as radical hysterectomy, previous history for treatment of stress urinary incontinence either medical (type, duration \& result) or surgical (type, results).

2) Physical and gynecologic examination:

a) General Examination: Including Obesity and body mass index (BMI). 


\section{b) Abdominal Examination:}

Abdominal palpation was done to determine if the patient has a distended bladder. This can be confirmed by ultrasound for postvoid residual urine.

c) Neurological Assessment and Rectal Examination:

A screening neurological examination to assess sacral spine segments (S2 - S4) and the important nerves controlling micturition with focusing on reflexes and anal tone.

d) Vaginal Examination:

To exclude genitourinary fistula and any associated pelvic organ prolapse.

\section{Cough Stress Test:}

The patient was asked to cough repetitively with a bladder volume of at least $300 \mathrm{ml}$ or a subjectively full bladder in the lithotomy and/or standing position.

Small spurts of urine lost immediately with coughing are suggestive of stress incontinence. A large volume of urine loss suggests that another cause of incontinence should be pursued. The standing position gives more consistent results (84\%) than does the supine position (40\%).

\section{3) Investigations:}

\section{Urodynamics}

All patients underwent urodynamic evaluation preoperatively in the Urodynamic unit in the outpatient clinic in Zagazig University Hospital using Multichannel Urodynamics System (Triton, LA BORIE, Toronto, Canada).

\section{The study included}

Free Uroflowmetry

Fluid filling Cystometry with stress on Valsava leak point pressure (VLPP).

Uroflowmetry was done in all patients to exclude those with low Qmax $(<15$ $\mathrm{m} / \mathrm{sec}$ ) indicating obstruction or impaired bladder contractility.

Filling Cystometry: The presence of involuntary detrusor contractions with or without incontinence was documented, and VLPP was obtained at a bladder volume of $200 \mathrm{~mL}$. Pressure flow study was subsequently performed with maximum cystometric capacity. The Valsalva leak point pressure (VLPP) was measured by asking the patient to perform a valsalva maneuver when the patient's bladder was comfortably full with $200 \mathrm{cc}$; urine leakage was seen by the examiner or recorded on uroflowmeter.

\section{Laboratory investigations:}

Mid-stream urine analysis and culture and sensitivity test if pyuria was present to be treated before any intervention, CBC, RFT, LFT, random blood sugar and coagulation profile.

\section{Manipulation:}

Regional -spinal anesthesia-(saddle block).

Lithotomy position with flexed hips at 90 - 100 degree.

\section{Insertion (Contasure-Needleless ${ }^{\circledR}$ )}

1) Vaginal incision: $2 \mathrm{~cm}$ longitudinal incision at the anterior vaginal wall at the level of middle urethra (Figure 1). 


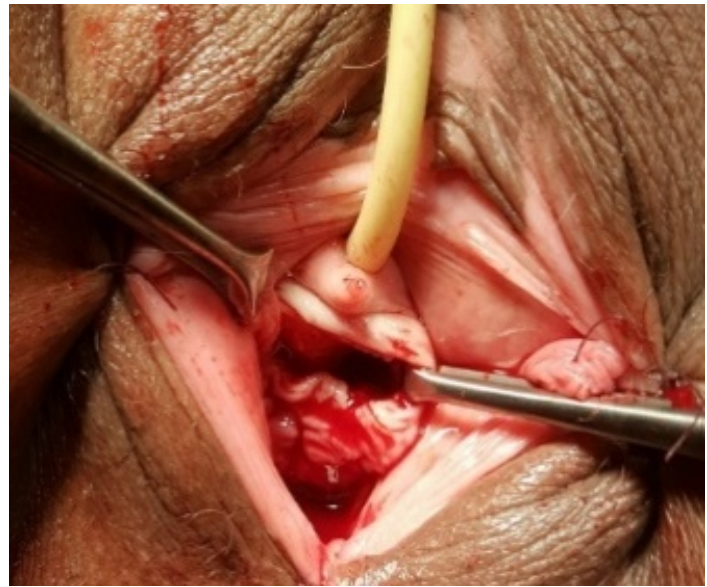

Figure 1. Vaginal incision.

2) Wideperi-urethral scissor dissection at 2 and 10 o'clock to easily accept the Mesh fully extended (mesh is $1.2 \mathrm{~cm}$ wide), only up to the ischiopubic ramus.

3) Insert the tip of the forceps inside the NL pocket. Hyperextend the forceps jaws and close it, creating an arrow with the mesh.

4) Forceps with mesh must be palm supported with the finger behind the sling holding the mesh extended, very important to avoid mesh twisting. The blue suture marks the midline (Figure 2).

5) Mesh insertion: At 10 o'clock. Push the mesh with forceps-palm supported-, until the blue suture is $1 \mathrm{~cm}$ deeper in reference to the urethra and extend (opening the forceps widely) the pocket inside the muscle (Figure 3 ).

-We use curved \& straight forceps. During using a curved one, the insertion was performed with tip facing us.

6) Withdraw the forceps semi-closing it. (Not completely open, not completely closed)

7) The forceps at 2 o'clock and push it until the blue suture is in the midline. Leave the mesh fully extended and in full contact under the urethra.

8) If an intra-operative adjustment is needed; turn upside-down the forceps (with the tip facing the patient) and follow the mesh until the tip of the forceps enters into the pocket and push up to increase the sling tension (Figure 4).

9) Cut the blue suture and close vaginal incision. Withdraw the catheter.

Transobturator Tension Free Vaginal tape insertion (in-out technique):

After incision and dissection of paraurethral tissues then, another two right and left incisions were made in the inguinal crease at level of the clitoris. The needle with the tape is passed in obturator fascia-most anterior and inferior part of obturator fossa-until it reached skin incision, the tape is hung out from tape, then the needle pulled out through vaginal incision. The steps are then repeated again on the other side. The tape is adjusted to be tension free.

Finally, incisions are closed with $2 / 0$ sutures and a vaginal pack is left with the urethral catheter in situ for $24 \mathrm{~h}$ (then remove catheter, follow up 2 hours, then discharge patient).

Statistical analysis 


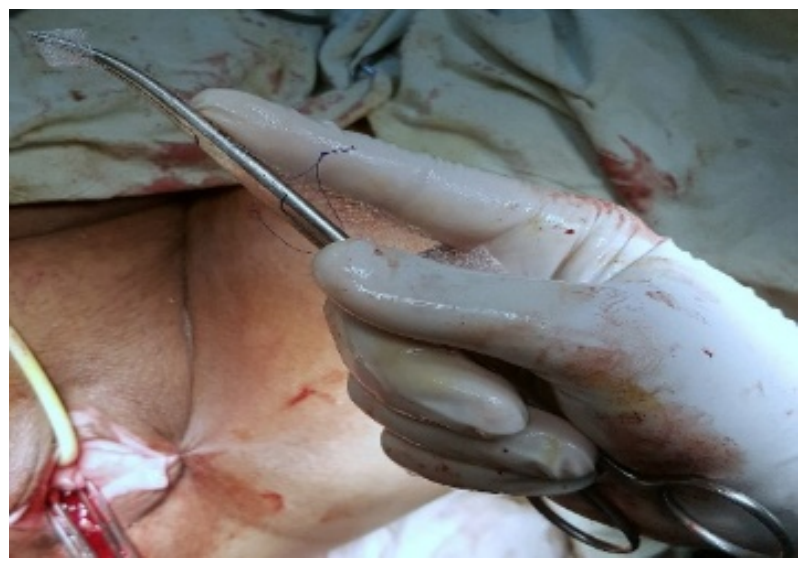

Figure 2. Handling of contasure.

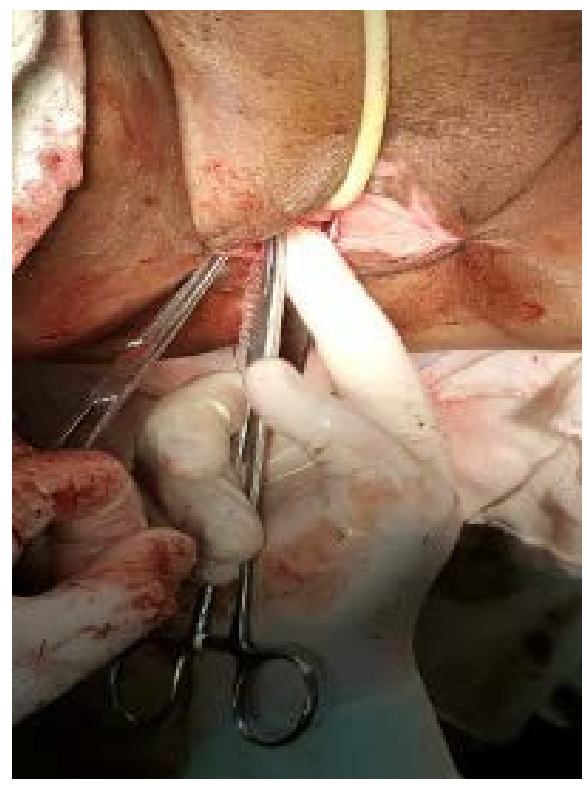

Figure 3. Insertion of contasure.

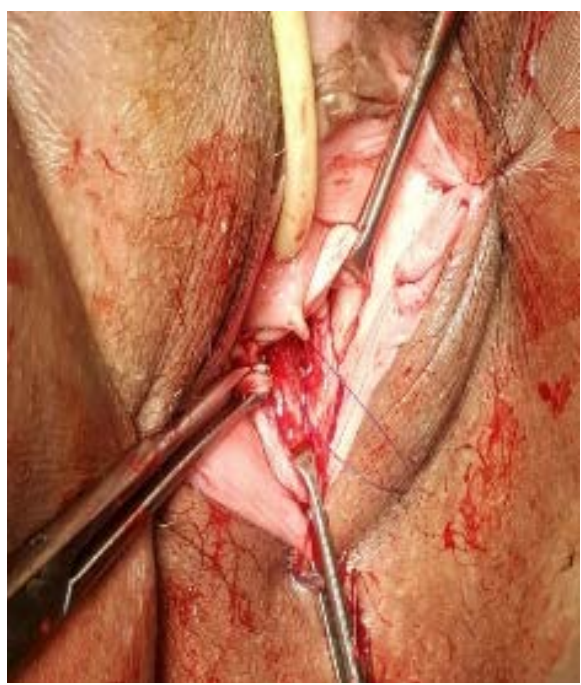

Figure 4. Bluesurure adjustment. 
Data were entered checked and analyzed using Epi-Info version 6 and SPP for Windows version 8 .

\section{Result}

Table 1. Comparison between the studied groups regarding demographic characteristics and obstetric history.

\begin{tabular}{|c|c|c|c|c|}
\hline \multirow{3}{*}{$\begin{array}{c}\text { Demographic } \\
\text { characteristics and } \\
\text { obstetric history }\end{array}$} & \multicolumn{2}{|c|}{ Operation } & \multicolumn{2}{|c|}{ Test } \\
\hline & Trans-obturator tape & Mini-sling operation & \multirow{2}{*}{$X^{2} / t / Z$} & \multirow{2}{*}{$\mathrm{p}$} \\
\hline & $\mathrm{N}=20(\%)$ & $\mathrm{N}=20(\%)$ & & \\
\hline \multicolumn{5}{|l|}{ Menopause: } \\
\hline No & $13(65)$ & $15(75)$ & \multirow{2}{*}{0.476} & \multirow{2}{*}{0.49} \\
\hline Yes & $7(35)$ & $5(25)$ & & \\
\hline \multicolumn{5}{|l|}{ Age (years): } \\
\hline Mean \pm SD & $45.9 \pm 9.29$ & $44.35 \pm 6.9$ & \multirow{2}{*}{$\mathrm{t}(0.599)$} & \multirow{2}{*}{0.553} \\
\hline Range & $28-60$ & $31-57$ & & \\
\hline \multicolumn{5}{|l|}{ Parity: } \\
\hline Mean \pm SD & $3.8 \pm 0.95$ & $3.2 \pm 0.83$ & \multirow{3}{*}{$\mathrm{Z}(-1.949)$} & \multirow{3}{*}{0.051} \\
\hline Median & 4 & 3 & & \\
\hline Range & $2-6$ & $2-5$ & & \\
\hline \multicolumn{5}{|l|}{ BMI $\left(\mathrm{kg} / \mathrm{m}^{2}\right)$ : } \\
\hline Mean \pm SD & $28.1 \pm 4$ & $27.8 \pm 4.84$ & \multirow{2}{*}{$\mathrm{t}(0.214)$} & \multirow{2}{*}{0.832} \\
\hline Range & $21-37$ & $21-37$ & & \\
\hline
\end{tabular}

Table 2. Comparison between the studied groups regarding VLPP.

\begin{tabular}{ccccc}
\hline & \multicolumn{2}{c}{ Operation } & \multicolumn{2}{c}{ Test } \\
\cline { 2 - 3 } VLPP & \multicolumn{2}{c}{ Trans-obturator tape } & Mini-sling operation & \\
\cline { 2 - 3 } & $\mathrm{N}=20(\%)$ & $\mathrm{N}=20(\%)$ & $\mathrm{P}$ \\
\hline 100 & $6(30)$ & $7(35)$ & \\
$60-75$ & $10(50)$ & $9(45)$ & 0.13 & 0.937 \\
$80-100$ & $4(20)$ & $4(20)$ & & \\
\hline
\end{tabular}

Table 3. Comparison between the studied groups regarding intraoperative data.

\begin{tabular}{|c|c|c|c|c|}
\hline \multirow{3}{*}{ Intraoperative data } & \multicolumn{2}{|c|}{ Operation } & \multicolumn{2}{|c|}{ Test } \\
\hline & Trans-obturator tape & Mini-sling operation & \multirow{2}{*}{$t$} & \multirow{2}{*}{$\mathrm{p}$} \\
\hline & $N=20(\%)$ & $\mathrm{N}=20(\%)$ & & \\
\hline \multicolumn{5}{|l|}{ Operative time (minutes) } \\
\hline Mean \pm SD & $18.25 \pm 2.2$ & $17.1 \pm 1.8$ & \multirow{2}{*}{1.809} & \multirow{2}{*}{0.078} \\
\hline Range & $15-23$ & $14-20$ & & \\
\hline \multicolumn{5}{|l|}{ Blood loss (ml) } \\
\hline Mean \pm SD & $77.9 \pm 16.53$ & $62.55 \pm 6.49$ & \multirow{2}{*}{3.866} & \multirow{2}{*}{$0.001^{\star *}$} \\
\hline Range & $50-105$ & $47-74$ & & \\
\hline \multicolumn{5}{|l|}{ Pain scale: } \\
\hline Median & 2 & 1 & \multirow{2}{*}{-1.929} & \multirow{2}{*}{0.054} \\
\hline Range & $0-6$ & $0-4$ & & \\
\hline
\end{tabular}


Table 4. Comparison between the studied groups regarding cough test at 3, 6 and 12 months.

\begin{tabular}{|c|c|c|c|c|}
\hline \multirow{3}{*}{ Cough test } & \multicolumn{2}{|c|}{ Operation } & \multicolumn{2}{|c|}{ Test } \\
\hline & \multicolumn{2}{|c|}{ Trans-obturator tape Mini-sling operation } & \multirow{2}{*}{$X^{2}$} & \multirow{2}{*}{$\mathrm{p}$} \\
\hline & $N=20(\%)$ & $\mathrm{N}=20(\%)$ & & \\
\hline \multicolumn{5}{|l|}{ At 3 months: } \\
\hline Negative & $16(84)$ & $14(70)$ & \multirow{2}{*}{ Fisher } & \multirow{2}{*}{1} \\
\hline Positive & $4(16)$ & $6(30)$ & & \\
\hline At 6 months: & $\mathrm{N}=18$ & $\mathrm{~N}=19$ & & \\
\hline Negative & $15(83.3)$ & $15(78.9)$ & \multirow{2}{*}{ Fisher } & \multirow{2}{*}{1} \\
\hline Positive & $3(16.7)$ & $4(21.1)$ & & \\
\hline At 12 months: & $\mathrm{N}=18$ & $\mathrm{~N}=18$ & \multirow{4}{*}{ Fisher } & \multirow{4}{*}{1} \\
\hline Negative & $15(83.3)$ & $14(77.8)$ & & \\
\hline Positive & $3(16.7)$ & $4(22.2)$ & & \\
\hline $\mathrm{P}(\mathrm{Q})$ & 1 & 1 & & \\
\hline
\end{tabular}

There were 2 missed cases in follow up in each arm of study.

Table 5. Relation between cough test after 6 months and BMI among the studied patients.

\begin{tabular}{cccc}
\hline & BMI & \multicolumn{2}{c}{ Test } \\
\hline \multirow{2}{*}{ Cough test after 6 months } & Mean \pm SD & t & p \\
\cline { 2 - 4 } & $27.28 \pm 4.2$ & & \\
Negative & $29.43 \pm 5.56$ & -1.143 & 0.261 \\
Positive & & \\
\hline
\end{tabular}

Table 6. Comparison between the studied groups regarding postoperative complications.

\begin{tabular}{ccccc}
\hline & \multicolumn{2}{c}{ Operation } & \multicolumn{2}{c}{ Test } \\
\cline { 2 - 3 } Complications & Trans-obturator tape & Mini-sling operation & \multirow{2}{*}{$X^{2}$} & $\mathrm{p}$ \\
\cline { 2 - 3 } & $\mathrm{N}=\mathbf{2 0}(\%)$ & $\mathbf{N}=\mathbf{2 0}(\%)$ & & \\
\hline Pain & & & Fisher & 0.661 \\
No & $16(80)$ & $19(95)$ & & \\
Yes & $4(20)$ & $1(5)$ & Fisher & 1 \\
Site & $2(10)$ & $1(5)$ & Fisher & 0.487 \\
Groin & $2(10)$ & $0(0)$ & & \\
Thigh & & & Fisher & 0.605 \\
Urinary: & $2(10)$ & $3(15)$ & Fisher & 0.231 \\
UTI & $0(0)$ & $1(5)$ & & \\
Urine retention & & & Fisher & 1 \\
Dyspareunia: & $18(90)$ & $19(95)$ & & \\
\hline Negative & $2(10)$ & $1(5)$ & & \\
Positive & & & & \\
\hline
\end{tabular}

There is statistically non-significant difference between the studied groups regarding presence of pain or its site, urinary complications or dyspareunia. 
Table 7. Relation between VLPP and cough stress reflex at 12 months among the studied patients.

\begin{tabular}{ccccc}
\hline & \multicolumn{2}{c}{ Cough stress test } & \multicolumn{2}{c}{ Test } \\
\cline { 2 - 3 } VLPP & Negative & Positive & $X^{2}$ & $\mathrm{p}$ \\
\cline { 2 - 3 } & $\mathrm{N}=29(\%)$ & $\mathrm{N}=7(\%)$ & & \\
\hline$>100$ & $10(34.5)$ & $1(14.3)$ & & \\
$60-75$ & $2(6.9)$ & $6(71.4)$ & 15.046 & $0.001^{* *}$ \\
$80-100$ & $17(58.6)$ & $1(14.3)$ & & \\
\hline
\end{tabular}

${ }^{*} \mathrm{P}>0.05$ is statistically non-significant.

There is statistically significant relation between cough test among the studied groups and VLPP. The largest percentage of patients who had negative cough test had VLPP from $80-100$ and $>100$.

There is statistically non-significant difference between the studied groups regarding age, parity, BMI or menstrual status (Table 1, Table 2). There is statistically non-significant difference between the studied groups regarding VLPP (the largest percentage of patients within both groups had incontinence at 60 75 (Table 7). There is statistically non-significant difference between the studied groups regarding operative time (TOT took non-significantly longer time 18.25 minutes versus 17.1 minutes in mini-sling operation (Table 3 ). There is statistically significant difference between the two techniques regarding blood loss (significantly higher in TOT). There is statistically non-significant difference between the two techniques regarding postoperative pain scale (Table 6). There is statistically non-significant difference between the studied groups regarding cough test at 3,6 and 12 months (Table 4). Similarly, there is non-significant change in cough test over time. There is non-significant relation between cough test after 6 months and BMI among the studied patients (Table 5).

\section{Discussion}

Stress urinary incontinence is great obstacle against female quality of life. Understanding mid-urethral role of urinary continence had opened way to introduce mid-urethral trans-vaginal tape (TVT) as gold standard method in treating SUI, which was upgraded continuously till reaching Contasure single incision minisling. Contasure had introduced with less complications, only one small vaginal incision, small mesh introduction and nearly equal efficacy [11].

Stress urinary incontinence (SUI) is a common disease of middle and old aged women. Its prevalence rate in adult female is about $18.9 \%$ while higher prevalence $28 \%$ occur in their 50 s. TVT proposed by Ulmsten and other doctors [12] as well as TOT proposed by Delorme are considered as standard mid-urethral slings (SMUS). However, having been considered to have the advantages of smaller wounds, less pains, shorter length of stay and more rapid postoperative recovery, the recent single incision mini slings (SIMS) is getting its popularity gradually. As a branch of SIMS, Needleless slings implantation technique applies 
the approach of single-incision to anterior vaginal wall and mid-urethral, theoretically avoiding the bladder and its perforation in TVT and obturator nerve injury in TOT.

A multi-center study Martinez \& Tardiu [10] in Spain in 2006-2010 showed that among 131 patients, who were performed Needleless slings implantation, $84 \%$ of them were cured while $6 \%$ of them had symptomatic improvement.

Ogah [13] compared the curative effect of Needleless slings implantation and TVT-O as well as followed up the patients for 24 months. The result turned out to be the same between the two types of operation. And patients who were performed Needleless slings implantation showed a higher degree of surgical satisfaction.

Karateke and other doctors, [6] performed Needleless slings implantation on 50 patients with SUI and followed them up with an average period of 433.5 days. $96 \%$ of the patients showed a higher satisfaction in quality of life. It was found in this paper that Needleless slings implantation obviously out-performed TOT in length of surgery, intraoperative hemorrhage volume and length of stay.

Baseline characteristics in our thesis showed statistically non-significant difference between the two group as in Mean age that was $45.9 \pm(9.29)$ \& 44.35 $\pm(6.9)$, mean parity was $3.8 \pm(0.95) \& 3.2 \pm(0.83)$, mean BMI $28.1 \pm(4) \& 27.8$ $\pm(4.84)\left(\mathrm{kg} / \mathrm{m}^{2}\right)$ in TVT-o \& Contasure ${ }^{\circledR}$ respectively. Thus both groups are homogenously selected.

In this study, we used negative Cough stress test as objective cure parameter which was negative in $78.9 \%$ \& $83.3 \%$ in Contasure and TVT- $\mathrm{O}^{\circledR}$ group respectively. These results nearly equal to Franco E. \& Tardiu L. (2014), who had negative cough test in $88.9 \%$ \& $84.7 \%$ [10].

The subjective cure rate was $88.8 \%$ in Contasure \& $94.4 \%$ TVT-O ${ }^{\circledR}$ group. That was accepted by Tsia-Shu Lo et al. who had subjective cure rate 93\% [14].

There is statistically non-significant difference between the studied groups regarding operative time (TOT took non-significantly longer time 18.25 minutes versus 17.1 minutes in mini-sling operation). Also, there is statistically significant difference between the two techniques regarding blood loss (significantly higher by $15.35 \mathrm{ml}$ in TOT), these results were not constant with Tommaselli GA et al. [15], who had average operative time 12 \& 7.8 minutes in TVT-O \& SIS respectively, but their average BMI was 19.5 and the SIS was TVT-secure.

There is statistically non-significant difference between the studied groups regarding VLPP (the largest percentage of patients within both groups had incontinence at 60 - 75).

Studies performed by Martinez et al. [10], on 250 patients with 3 years follow up; showed that postoperative puncture was confined to obturator membrane and did not penetrate obturator externus, thus there was no injury of tendon and no obvious pain in groin/thigh. During the long-term follow-up, none of the patients in Needleless group had the pain in groin/thigh, while there were two cases in the TOT group having recalcitrant pain in inguinal region/femoribus in- 
ternus. However, there was no statistical difference in VAS scores between two groups. The above proved that Needleless surgery owned obvious advantage in reducing postoperative pain.

Taner et al. [16] showed almost three times higher erosion rates $(\mathrm{p}=0.036)$ in the mini-sling group compared with the TOT over a lyear follow-up. However, this might be related to the surgeon's experience since the research assistants also participated in the study. They assessed the impact of surgeon experience on mesh-based procedures for SUI in their population-based retrospective cohort study including 59,887 women. It was found that patients of low volume surgeons were significantly more likely to experience mesh-related complications after surgery for SUI (HR, 1.37 (95\% CI, 1.21 - 1.55); $\mathrm{p}<0.01$ ).

Sivaslioglu et al. [17] compared outside-in TOT with the mini-sling $\left(\mathrm{TFS}^{\circledR}\right)$ at 5 -year follow-up. Objective cure rates were significantly higher $(\mathrm{p}=0.029)$ in the mini-sling group compared with TOT, while the subjective cure rates were similar. Objective and subjective cure rates were similar among the studies comparing the trans-obturator and mini-slings for a 12-month period [16] [18] [19] [20].

Mostafa et al. [9] found lower intensity and shorter duration of postoperative pain in the mini-sling group compared with the TVT-O group.

Karakeci A. et al. [21] compared the outcomes of the mini-sling and TOT at 12 months. The objective cure rate was worse with SIMS (68.1\% versus 81.9\%) compared with the TOT group although thigh pain was greater after TOT.

Franco and Tardiu found similar functional outcomes and satisfaction levels between the Contasure-Needleless mini-sling and TOT groups at long-term follow-up of at least 3 years in patients with positive stress tests associated with or without genital prolapse. Our study exhibits similar findings in a cohort without pelvic organ prolapse [10].

The major strength of the present study is that all surgeries were performed by the same experienced urogynecology surgeon and on patients without significant pelvic organ prolapse who did not need further or concomitant POP surgery. Additionally, all complications were uniformly classified utilizing the standard IUGA/ICS classification system. This system was designed to be a common language for providers to communicate consistently regarding complications and to be a universal system for collecting data on mesh-related complications. Tunitsky et al. assessed the inter-rater reliability of the IUGA/ICS classification system and found it had poor reliability $(\kappa=0.15-0.78)$ [22].

This study is a single-center one with small sample capacity. The follow-up time so far is only one year, which means that the study still lacks long-term follow-up results such as results of 3 or 5 years after surgery. During the later period, the study will continue to expand the amount of samples and meanwhile, further research about the long-term therapeutic effects of the single-incision Needleless sling will be done.

Pain VAS score was lower in SIS with median 2 \& 1 in TVT-o \& SIS. These results nearly like Tommaselli GA 2015 with mean $2.8 \& 0.7$ respectively [18]. 
There is statistically non-significant difference between the two techniques regarding postoperative pain scale. No serious complications were reported, no urgency developed, despite the description of serious complications in the literature; thus in our opinion; both techniques seem to be safe. These data were accepted by Grison P. et al. who compared two methods on 92 cases [19].

In our thesis: Only one case (5\%) reported urine retention after SIS, which is relieved after 1 day from re-catheterization, this is accepted incidence with Novara G. et al., who had incidence between $2.7 \%$ to $11.2 \%$ [23].

There is statistically non-significant difference between the studied groups regarding presence of pain or its site, urinary complications or dyspareunia.

In theory, due to the design of two-piece $\mathrm{T}$ sling, Needleless sling is able to be fixed into the obturator internus, and the contact area of the sling in midurethral is similar to TOT surgery. As a consequence, its long-term curative effect can be similar to TOT. In this study, our patient showed no statistical difference in ICIQ-SF scores of patients in both groups after surgery, but there were significant differences compared to the preoperative data. For patients of both groups, the ICIQ-SF showed that their life quality was greatly improved after operation, the result of which was similar to the reports of related literature [9] [10].

So, there is non-significant difference between the studied groups regarding ICIQ-IU pre or postoperatively. Within each group, in Figure 5 there is significant decrease in ICIQ-IU over time, with positive effect on our patient's sexual life, these results are in agreement with Soliman T.S. [20].

There is statistically significant relation between negativity of cough stress test-post operatively-among the studied groups and VLPP. this also supported by O'Connor RC et al., 2006, but Toledo L. et al. 2012 denied any prongostic relation [24] [25].

In conclusion, our experience and the results in 1-year follow-up of non-inferiority of the Contasure ${ }^{\circledR}$ compared to TVT-O Kim ${ }^{\circledR}$, demonstrate that it is a safe technique, reproducible, and accomplishes the goal of minimally invasive surgery.
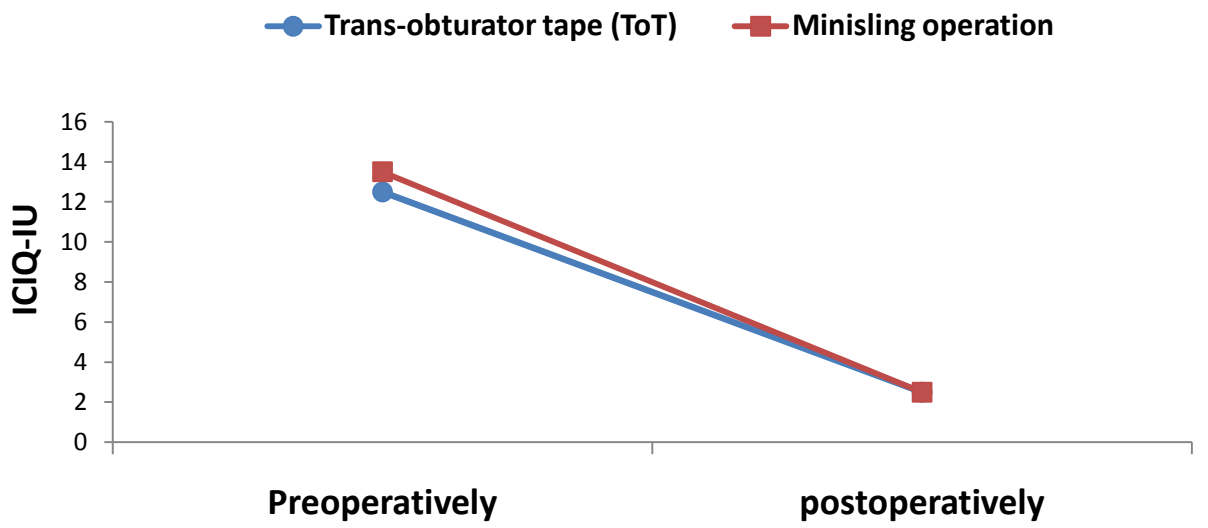

Figure 5. Multiple line graph showing comparison between the studied groups regarding ICIQ-IU pre and postoperatively. 


\section{Conclusion}

We conclude that compared with the TOT surgery, single-incision Needleless sling in the treatment of female stress urinary incontinence is simpler and quicker and has less hemorrhage during surgery as well as faster recovery and it also can obviously reduce the inguinal region pains after operation and shorten hospital stays. In summary, single-incision Needleless sling is a kind of convenient, safe and effective minimally invasive surgery for urinary incontinence. Our experience in recent years with single-incision sling for women requiring surgery for stress incontinence has been good, in particular for those women with a high operative risk, previous operations in the retro-pubic space, an increased tendency to hemorrhage or excessive scar formation. Particularly evident are the greatly reduced invasiveness of the mini-slings and the low rate of pain symptoms.

\section{Acknowledgements}

The authors are grateful for the patients without whom this study would not have been done.

\section{Funding Sources}

The authors have no funding to report.

\section{Conflicts of Interest}

The authors declare no conflict of interest.

\section{References}

[1] Chong, E.C., Khan, A.A. and Anger, J.T. (2011) The Financial Burden of Stress Urinary Incontinence among Women in the United States. Current Urology Reports, 12, 358-362. https://doi.org/10.1007/s11934-011-0209-x

[2] Elser, D. (2010) Stress Urinary Incontinence: What Qualities Do Women Seek in Treatment? OBG Management Supplement, 20, S1-S2.

[3] Thuroff, J.W., Abrams, P., Andersson, K.E., et al. (2011) EAU Guidelines on Urinary Incontinence. European Urology, 59, 387-400. https://doi.org/10.1016/j.eururo.2010.11.021

[4] Osborn, D.J., Matthew, G., et al. (2013) Obesity and Female Stress Urinary Incontinence. Urology, 82, 759-763. https://doi.org/10.1016/j.urology.2013.06.020

[5] Ward, K. and Hilton, P. (2005) Minimally Invasive Synthetic Suburethral Slings: Emerging Complications. Obstetrics \& Gynecology, 7, 223-232. https://doi.org/10.1576/toag.7.4.223.27116

[6] Karateke, A., Haliloglu, B., Cam, C., et al. (2009) Comparison of TVT and TVT-O in Patients with Stress Urinary Incontinence: Short-Term Cure Rates and Factors Influencing the Outcome. A Prospective Randomised Study. Australian and New Zealand Journal of Obstetrics and Gynaecology, 49, 99-105. https://doi.org/10.1111/j.1479-828X.2009.00957.x

[7] Ghoniem, G., Stanford, E., Kenton, K., et al. (2008) Evaluation and Outcome Measures in the Treatment of Female Urinary Stress Incontinence: International Urogy- 
necological Association (IUGA) Guidelines for Research and Clinical Practice. International Urogynecology Journal, 19, 5-33. https://doi.org/10.1007/s00192-007-0495-5

[8] Oliveira, R., Botelho, F., Silva, P., et al. (2011) Exploratory Study Assessing Efficacy and Complications of TVT-O, TVT-Secur, and Mini-Arc: Results at 12-Month Follow-Up. European Urology, 59, 940-944. https://doi.org/10.1016/j.eururo.2011.01.018

[9] Mostafa, A., Hopper, L., Abdel-Fattah, M., et al. (2014) Single-Incision Mini-Slings versus Standard Midurethral Slings in Surgical Management of Female Stress Urinary Incontinence: An Updated Systematic Review and Meta-Analysis of Effectiveness and Complications. European Urology, 65, 402-427. https://doi.org/10.1016/j.eururo.2013.08.032

[10] Martinez, F.E. and Tardiu, L.A. (2015) Contasure-Needleless Single Incision Sling Compared with Transobturator TVT-O for the Treatment of Stress Urinary Incontinence: Long-Term Results. International Urogynecology Journal, 26, 213-218. https://doi.org/10.1007/s00192-014-2475-x

[11] Capobianco, G., Madonia, M., Morelli, S., et al. (2018) Management of Female Stress Urinary Incontinence: A Care Pathway and Update. Maturitas, 109, 32-38. https://doi.org/10.1016/j.maturitas.2017.12.008

[12] Ulmsten, U., Abrams, P., Fall, M., et al. (2002) The Standardization of Terminology of Lower Urinary Tract Function: Report from the Standardization Subcommittee of the International Continence Society. Neurourology and Urodynamics, 21, 167-178.

[13] Ogah, J., Cody, J. and Rogerson, L. (2009) Minimally Invasive Synthetic Suburethral Sling Operations for Stress Urinary Incontinence in Women. Cochrane Database of Systematic Reviews, No. 4, CD006375. https://doi.org/10.1002/14651858.CD006375.pub2

[14] Lo, T.S., Shailaja, N., Chua, S., et al. (2019) Evaluation of Clinical Outcome and Risk Factors for Failure of Single-Incision Midurethral Short Tape Procedure (Solyx Tape) for Stress Urinary Incontinence. Journal of Minimally Invasive Gynecology, 26, 688-694. https://doi.org/10.1016/j.jmig.2018.07.013

[15] Tommaselli, G.A., D’Afiero, A., Di Carlo, C., et al. (2013) Tension-Free Vaginal Tape-O and -Secur for the Treatment of Stress Urinary Incontinence: A Thirty-Six-Month Follow-Up Single-Blind, Double-Arm, Randomized Study. Journal of Minimally Invasive Gynecology, 20, 198-204. https://doi.org/10.1016/j.jmig.2012.11.008

[16] Taner, C.E., Golbasi, H. and Golbasi, C. (2019) Long-Term Outcomes and Quality of Life Effects of Single Incision Mini Sling Procedure in Stress Urinary Incontinence Patients. European Journal of Obstetrics \& Gynecology and Reproductive Biology, 234, 3. https://doi.org/10.1016/j.ejogrb.2018.12.030

[17] Sivaslioglu, A., Aydogmus, S., Celen, E., et al. (2010) A Prospective Randomized Controlled Trial of the Transobturator Tape and Tissue Fixation System Minisling in 80 Patient with Stress Urinary Incontinence-3 Year Results. Pelviperineology, 29, 56-59.

[18] Tommaselli, G.A., D’Afiero, A., Di Carlo, C., et al. (2015) Tension-Free Vaginal Tape-Obturator and Tension-Free Vaginal Tape-Secur for the Treatment of Stress Urinary Incontinence: A 5-Year Follow-Up Randomized Study. European Journal of Obstetrics \& Gynecology and Reproductive Biology, 185, 151-155.

https://doi.org/10.1016/j.ejogrb.2014.12.012 
[19] Grison, P., Tixier, S., Descamps, P., et al. (2018) Mini-Sling versus Transobturator Sling: Efficiency and Morbidity. Gynécologie Obstétrique Fertilité \& Sénologie, 46, 673-680. https://doi.org/10.1016/j.gofs.2018.09.008

[20] Soliman, T.S., Fathi, H., Kandeel, A., et al. (2017) Impact of Transobturator Vaginal Tape on Female Stress Urinary Incontinence and Sexual Function. Arab Journal of Urology, 15, 380-386. https://doi.org/10.1016/j.aju.2017.07.002

[21] Karakeci, A., Eftal, T.C., Keles, A., et al. (2020) Single-Incision Midurethral Sling Shows Less Pain and Similar Success Rate in a Short-Term Follow-Up Compared to the Transobturator Tape Method in the Treatment of Stress Urinary Incontinence. Turkish Journal of Urology, 46, 63-68. https://doi.org/10.5152/tud.2019.19105

[22] Tunitsky-Bitton, E., Murphy, A., Barber, M.D., et al. (2015) Assessment of Voiding after Sling: A Randomized Trial of 2 Methods of Postoperative Catheter Management after Midurethral Sling Surgery for Stress Urinary Incontinence in Women. American Journal of Obstetrics \& Gynecology, 212, 597.

https://doi.org/10.1016/j.ajog.2014.11.033

[23] Novara, G., Galfano, A., Boscolo-Berto, R., et al. (2008) Complication Rates of Tension-Free Midurethral Slings in the Treatment of Female Stress Urinary Incontinence: A Systematic Review and Meta-Analysis of Randomized Controlled Trials Comparing Tension-Free Midurethral Tapes to Other Surgical Procedures and Different Devices. European Urology, 53, 288-308. https://doi.org/10.1016/j.eururo.2007.10.073

[24] Toledo, L.G., Cabral, P.H., Casella, M.L., et al. (2012) Prognostic Value of Urethral Mobility and Valsalva Leak Point Pressure for Female Transobturator Sling Procedure. International Brazilian Journal of Urology, 38, 667-673. https://doi.org/10.1590/S1677-55382012000500012

[25] O’Connor, R.C., Anigian, D.K., Lyon, M.B., et al. (2006) Early Outcomes of Mid-Urethral Slings for Female Stress Urinary Incontinence Stratified by Valsalva Leak Point Pressure. Neurourology and Urodynamics, 25, 685-688. https://doi.org/10.1002/nau.20286

\section{List of Abbreviations}

SUI: Stress Urinary Incontinence

TVT $^{\circledR}$ : Tension-Free Vaginal Tape

TVT $^{\circledR}$-O: Transobturator-TVT ${ }^{\circledR}$

SIMS: Single Incision Mini-Slings

ICI-Q: International Incontinence Questionnaire

NL: Needless 